\title{
Detection of Asherman's syndrome after conservative management of placenta accreta: a case report
}

\author{
Kenro Chikazawa*, Ken Imai, Wang Liangcheng, Shigetane Sasaki, Isao Horiuchi, Tomoyuki Kuwata \\ and Kenjiro Takagi
}

\begin{abstract}
Background: We present a case involving conservative treatment of placenta accreta, with a subsequent diagnosis of Asherman's syndrome.

Case presentation: A 41-year-old Japanese woman (G2POA2) delivered a healthy male infant via cesarean section due to preeclampsia. The placenta did not spontaneously separate and was manually removed. Adhesion was tight and placenta accreta was diagnosed. During the procedure, no uterine inversion or perforation, and no uterine cavity adhesion, were observed. Four months postoperatively, hysteroscopy was performed. Adhesion was detected at the fundus of her uterus where the placenta had adhered to the uterus. Asherman's syndrome was diagnosed.

Conclusions: Asherman's syndrome might occur after conservative management of placenta accreta, which may be a direct cause of placenta accreta recurrence. When Asherman's syndrome is diagnosed, the site of the placenta and adhesion should be monitored during subsequent pregnancies.
\end{abstract}

Keywords: Placenta accreta, Conservative management, Asherman's syndrome

\section{Background}

Several recent reports have discussed the conservative management of placenta accreta [1, 2]; however, no established method currently exists. Moreover, the management of subsequent pregnancies after conservative treatment of placenta accreta has not been established. The recurrence rate of placental attachment disorder during subsequent pregnancies after conservative management of placenta accreta was reported to be $20 \%$ [3]. Given this high recurrence rate, the ability to predict the recurrence of placenta accreta would be useful.

Asherman's syndrome is associated with the risk of placenta accreta; out of all cases of Asherman's syndrome, $12.5 \%$ experience postpartum hemorrhage due to placenta accreta [4]. Here we present a case involving conservative treatment of placenta accreta, with a subsequent diagnosis of Asherman's syndrome. The present

\footnotetext{
* Correspondence: kendokenro@hotmail.com

Perinatal Center, Division of Maternal Fetal Medicine, Saitama Medical Center, Jichi Medical University, 1-847, Amanuma-cho, Omiya-ku, Saitama 330-8503, Japan
}

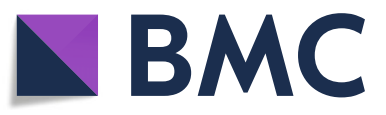

(c) The Author(s). 2018 Open Access This article is distributed under the terms of the Creative Commons Attribution 4.0 International License (http://creativecommons.org/licenses/by/4.0/), which permits unrestricted use, distribution, and reproduction in any medium, provided you give appropriate credit to the original author(s) and the source, provide a link to the Creative Commons license, and indicate if changes were made. The Creative Commons Public Domain Dedication waiver (http://creativecommons.org/publicdomain/zero/1.0/) applies to the data made available in this article, unless otherwise stated. case suggests that, after conservative treatment of placenta accreta, patients may progress to Asherman's syndrome. Thus, Asherman's syndrome following conservative treatment of placenta accreta might be a direct cause of placenta accreta recurrence.

\section{Case presentation}

A 41-year-old Japanese woman (gravida 2, para 0) had two previous miscarriages during the first trimester. She became pregnant via in vitro fertilization. Ultrasound findings during the second and third trimesters were not indicative of placenta accreta. She developed preeclampsia during the 36th week of gestation and underwent caesarean section. She delivered a healthy male infant $(2178 \mathrm{~g})$ with Apgar scores of 8 and 9 at 1 and 5 minutes, respectively. However, the placenta did not spontaneously separate; thus, the operator separated and gently removed the placenta from the uterine cavity manually. As adhesion was tight, placenta accreta was diagnosed. During the procedure, no uterine inversion or perforation was observed and there were no uterine cavity 
adhesions, such as those in Asherman's syndrome. Manual removal was successfully performed.

Continuous bleeding was observed after removal of the placenta; thus, uterine gauze packing was performed, and the bleeding was stopped. On postoperative day 1 , there was little bleeding; thus, the obstetrician removed the gauze. However, severe bleeding reoccurred. A balloon (Bakri॰ Balloon, Tokyo, Japan) was inserted into her uterine cavity and the bleeding stopped again. On postoperative day 3 , the balloon was removed and there was no active bleeding this time.

One month postoperatively, she had no abnormal complaints. Two months postoperatively, her menses restarted. Four months postoperatively, we performed hysteroscopy. We detected an adhesion at the fundus of her uterus, in the location of the placenta accreta (Fig. 1). Asherman's syndrome was diagnosed.

\section{Discussion and conclusions}

The present case indicates that Asherman's syndrome may occur after the conservative treatment of placenta accreta. The site of adhesion in the uterine cavity matched the location of the placenta accreta. Thus, Asherman's syndrome after the conservative treatment of placenta accreta might be a direct cause of placenta accreta recurrence.

The present study is the first to report hysteroscopic observations soon after the resumption of menses after the conservative treatment of placenta accreta. Although some reports exist regarding direct treatment with hysteroscopy for placenta accreta $[5,6]$, there are no previous reports of hysteroscopic observations following conservative treatment alone. The present case suggests that Asherman's syndrome may occur even without invasive uterine treatment. Legendre et al. [6] reported that, among four cases that underwent conservative treatment for placenta accreta, one ectopic pregnancy and one miscarriage occurred. Thus, conservative treatment for placenta accreta might be a cause of adhesions in the uterine cavity. Roy et al. [4] reported that the conception rate in patients with Asherman's syndrome was $30-58 \%$, with a miscarriage rate of $11.1 \%$. Considering these findings, undiagnosed Asherman's syndrome may exist after conservative treatment of placenta accreta, which may be a cause of placenta accreta recurrence after conservative treatment.

Severe postpartum hemorrhage due to placenta accreta has been observed in Asherman's syndrome [4]. In addition, $13 \%$ of cases with placenta accreta have a history of Asherman's syndrome [7]. The detection of abnormal findings in the uterine cavity on hysteroscopy after conservative treatment of placenta accreta would indicate the importance of considering the site of the placenta and adhesion in subsequent pregnancies. Conventional two-dimensional ultrasonography is useful in screening for placenta accreta, with both sensitivity and specificity over $90 \%$, and a negative predictive value of $98 \%$ [8-10]. Patients with a medical history of Asherman's syndrome after conservative management of placenta accreta should be examined by a skilled sonographer, who should be vigilant for the recurrence of placenta accreta. In addition, such patients should be managed in a critical care medical center with skilled clinicians, given the risk of severe postpartum hemorrhage.

This case report had a limitation. There were no data on pre-pregnancy hysteroscopy. Thus, we did not know whether the adhesion existed before in vitro fertilization.

In conclusion, Asherman's syndrome might occur after conservative management of placenta accreta, which may be a direct cause of recurrence. Observations by hysteroscopy are useful for arriving at the correct diagnosis. When Asherman's syndrome is diagnosed, the site of the placenta and adhesion should be monitored during subsequent pregnancies.
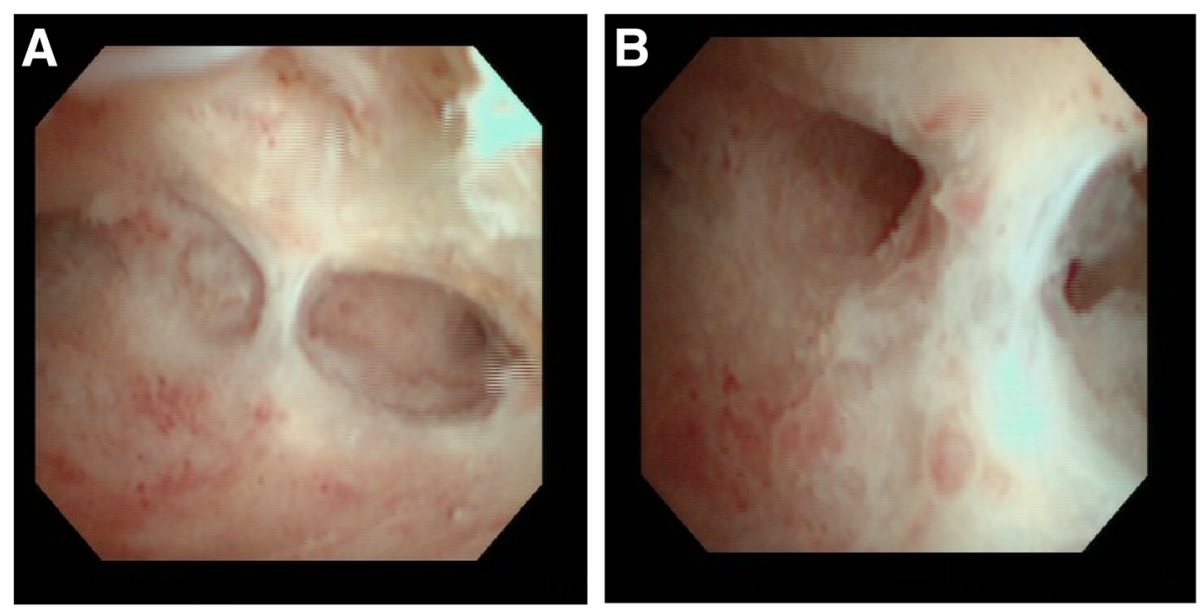

Fig. 1 Post-treatment hysteroscopy detected adhesion at the fundus of the uterus. a Distant view, b close view 


\section{Acknowledgements}

We would like to thank Editage (www.editage.com) for English language editing and publication support.

\section{Funding}

None

\section{Availability of data and materials}

The data that support the findings of this study are available from the medical records. Data are however available from the authors upon reasonable request.

\section{Authors' contributions}

$\mathrm{KC}$ and $\mathrm{KI}$ substantially contributed to the conception or design of the work, and the acquisition, analysis, or interpretation of data for the work. KC and WL were involved in drafting the work. SS critically reviewed the important intellectual content. IH, TK, and KT provided the final approval of the version to be published. All authors agree to be accountable for all aspects of the work in ensuring that questions related to the accuracy or integrity of any part of the work are appropriately investigated and resolved. All authors read and approved the final manuscript.

\section{Ethics approval and consent to participate}

Informed consent was obtained in comprehensive agreement.

\section{Consent for publication}

Written informed consent was obtained from the patient for publication of this case report and any accompanying images. A copy of the written consent is available for review by the Editor-in-Chief of this journal.

\section{Competing interests}

The authors declare that they have no competing interests.

\section{Publisher's Note}

Springer Nature remains neutral with regard to jurisdictional claims in published maps and institutional affiliations.

Received: 26 March 2018 Accepted: 3 October 2018

Published online: 20 November 2018

\section{References}

1. Clausen C, Lonn L, Langhoff-Roos J. Management of placenta percreta: a review of published cases. Acta Obstet Gynecol Scand. 2014;93:138-43.

2. Kim TH, Lee HH. Conservative management of abnormally invasive placenta after vaginal delivery. Acta Obstet Gynecol Scand. 2014;93:123-4.

3. Cunningham KM, Anwar A, Lindow SW. The recurrence risk of placenta accreta following uterine conserving management. J Neonatal Perinatal Med. 2015;8:293-6.

4. Roy KK, Baruah J, Sharma JB, Kumar S, Kachawa G, Singh N. Reproductive outcome following hysteroscopic adhesiolysis in patients with infertility due to Asherman's syndrome. Arch Gynecol Obstet. 2010;281:355-61.

5. Greenberg JA, Miner JD, O'Horo SK. Uterine artery embolization and hysteroscopic resection to treat retained placenta accreta: A case report. J Minim Invasive Gynecol. 2006;13:342-4.

6. Legendre G, Zoulovits FJ, Kinn J, Senthiles L, Fernandez H. Conservative management of placenta accreta: hysteroscopic resection of retained tissues. J Minim Invasive Gynecol. 2014;21:910-3.

7. Schenker JG, Margalioth EJ. Intrauterine adhesions: an updated appraisal. Fertil Steril. 1982;37:593-610.

8. D'Antonio F, lacovella C, Bhide A. Prenatal identification of invasive placentation using ultrasound: systematic review and meta-analysis. Ultrasound Obstet Gynecol. 2013;42:509-17.

9. Warshak CR, Eskander R, Hull AD, Scioscia AL, Mattrey RF, Benirschke K, et al. Accuracy of ultrasonography and magnetic resonance imaging in the diagnosis of placenta accreta. Obstet Gynecol. 2006;108:573-81.

10. Comstock CH, Love JJ Jr, Bronsteen RA, Lee W, Vettraino IM, Huang RR, Lorenz RP. Sonographic detection of placenta accreta in the second and third trimesters of pregnancy. Am J Obstet Gynec. 2004;190:1135-40.

\section{Ready to submit your research? Choose BMC and benefit from:}

- fast, convenient online submission

- thorough peer review by experienced researchers in your field

- rapid publication on acceptance

- support for research data, including large and complex data types

- gold Open Access which fosters wider collaboration and increased citations

- maximum visibility for your research: over $100 \mathrm{M}$ website views per year

At BMC, research is always in progress.

Learn more biomedcentral.com/submissions 